\title{
Evaluación audiológica en niños con sospecha de infección congénita por el virus zika
}

Audiological evaluation in children with suspected congenital zika virus infection

\begin{abstract}
Filiación:
${ }^{1}$ Audiólogas independientes,

Cartago, Costa Rica.

2 Soniclinic, Curridabat, San José, Costa Rica.

Instituto Costarricense de Investigación y Enseñanza en Nutrición y Salud-INCIENSA, Cartago, Costa Rica y Universidad Santa Paula, San José, Costa Rica.

Correspondencia: $\square$ Anabelle Sánchez Marín, correo electrónico: anasanma85@gmail.com

$----------$

Forma de citar: AguilarCalderón $F$, Sánchez-Marín A, Chaves-Jiménez G., BenavidesLara A. Evaluación audiológica en niños con sospecha de infección congénita por el virus zika. Rev Ter. 2022;16(1): 8-23.
\end{abstract}

Financiamiento:

Ninguno

Conflictos de Interés:

Ninguno

Abreviaturas: CREC, Centro de Registro de Enfermedades Congénitas; CODEPEH, Comisión para la Detección Precoz de la Hipoacusia Infantil; EOA, emisiones otacústicas auditivas; HNS, hipoacusia neurosensorial; INCIENSA, Instituto Costarricense de Investigación y Enseñanza en Nutrición y Salud; OMS, Organización Mundial de la Salud ORL, otorrinolaringólogo; PA, pérdida auditiva; PAPPS, programa de actividades preventivas y de promoción de la salud; PEATC, potenciales evocados auditivos de tallo cerebral; PEAA, potenciales evocados auditivos automatizados; PEATC, potenciales evocados auditivos de tallo cerebral; RN, recién nacido; SZC, sindrome de zika congénito; VZ, virus de zika. Fecha de envío: 18 de junio del 2021.

Fecha de aceptación: 28 de noviembre del 2021.

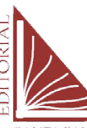

Ferllini Aguilar-Calderón ${ }^{1}$, Anabelle Sánchez-Marín ${ }^{1} \square$, Graciela Chaves-Jiménez² Adriana Benavides-Lara $^{3}$

\section{Resumen}

Introducción: entre el 2014 y 2018 el virus zika, cuyos reportes de casos previos en humanos fueron esporádicos, causó brotes extensos en América, los cuales se tradujeron en un aumento en la prevalencia de defectos congénitos asociados con infección perinatal por este virus, principalmente microcefalia y alteraciones del sistema nervioso central. La hipoacusia es uno de los defectos congénitos descritos como parte del síndrome de zika congénito. Costa Rica, un país con zonas de alta densidad del vector transmisor, no escapó a esta realidad, siendo hoy un país endémico del virus. Objetivo: definir la evaluación audiológica idónea que deben tener los niños con infección congénita por virus zika, de acuerdo con la evidencia existente en la literatura. Metodología: estudio de revisión cualitativa de la literatura, basada en una búsqueda bibliográfica realizada entre junio del 2019 y junio del 2020 en las bases de datos Redalyc, Pubmed, y Scielo, utilizando como descriptores las palabras hearing loss AND zika, congenital zika OR zika virus; se seleccionaron artículos publicados del 2016 al 2020, en idiomas español, inglés y portugués. La selección de artículos, la extracción de datos y la evaluación de la calidad fueron realizadas por dos revisores independientes. Se incluyeron estudios que contengan evaluación auditiva de pacientes con infección por el virus del zika congénita o adquirida; y / o hipótesis o evidencias sobre la fisiopatología del deterioro auditivo asociado con el virus del zika; y / o recomendaciones sobre detección y seguimiento de pacientes con deterioro auditivo por el virus del zika. Se incluyeron en la revisión 41 artículos. Se propusieron algoritmos de evaluación en los niños hijos de madres con exposición al virus zika durante la etapa prenatal o sospecha de infección congénita. Resultados: la principal manifestación de deterioro auditivo asociado a zika congénito es la hipoacusia neurosensorial, las series de casos publicadas al respecto varían bastante en cuanto a prevalencia y dependen en gran parte del método de diagnóstico utilizado y el seguimiento. La pérdida auditiva en estos casos se puede derivar de lesiones en la vía auditiva tanto a nivel cortical como coclear; varios son los mecanismos de acción 
propuestos. El deterioro auditivo puede ser progresivo y de aparición tardía y la afectación puede ser de moderada a severa. Se ha comprobado una semejanza en las manifestaciones clínicas del virus zika con las del grupo TORCH, lo que establece una similitud en la configuración de la pérdida auditiva y sus posibles efectos retrococleares y de aparición tardía. Se propone un algoritmo de detección y seguimiento para esta población. Conclusión: la valoración audiológica de los niños hijos de madres afectadas por el zika durante el embarazo debe ser oportuna, continua e interdisciplinaria durante al menos sus dos primeros años de vida.

Palabras claves: zika congénito, hipoacusia, valoración audiológica.

\section{Abstract}

Introduction: between 2014 and 2018, the zika virus, whose reports of previous cases in humans were sporadic, caused extensive outbreaks in America, which resulted in an increase in the prevalence of congenital defects associated with perinatal infection by this virus, mainly microcephaly. and alterations of the central nervous system. Hearing loss is one of the birth defects described as part of congenital zika syndrome. Costa Rica, a country with areas of high density of the transmitting vector, did not escape this reality, being today an endemic country of the virus. Objective: to define the ideal audiological evaluation that children with congenital zika virus infection should have, according to the evidence in the literature. Methodology: a qualitative review study of the literature was carried out, based on a bibliographic search carried out between June 2019 and June 2020 in the Redalyc, Pubmed, and Scielo databases, using as descriptors the words Hearing loss AND zika, congenital zika OR zika Virus; Articles published from 2016 to 2020, in Spanish, English and Portuguese languages were selected. Two independent reviewers performed article selection, data extraction, and quality assessment. Studies containing auditory evaluation of patients with congenital or acquired zika virus infection were included; and / or hypotheses or evidence about the pathophysiology of hearing impairment associated with the zika virus; and / or recommendations were included on the detection and follow-up of patients with hearing impairment due to the zika virus. Forty-one articles were included in the review. Evaluation algorithms were proposed in children born to mothers with exposure to the zika virus during the prenatal stage or suspected congenital infection. Results: the main manifestation of hearing impairment associated with congenital zika is sensorineural hearing loss; the case series published in this regard vary considerably in terms of prevalence and largely depend on the diagnostic method used and the follow-up. Hearing loss in these cases can be derived from lesions in the auditory pathway at both the cortical and cochlear levels; several are the proposed mechanisms of action. Hearing impairment can be progressive and late-onset and the impairment can be moderate to severe. A similarity has been found in the clinical manifestations of the zika virus with those of the TORCH group, which establishes a similarity in the configuration of hearing loss and its possible retrocochlear and late-onset effects. A detection and monitoring algorithm is proposed for this population. Conclusions: The audiological evaluation of children of mothers affected by VZ during pregnancy should be timely, continuous, and interdisciplinary during at least the first two years of life.

Keywords: congenital zika, hearing loss, audiological evaluation. 


\section{Introducción}

La audición es la vía fundamental por la que el niño desarrolla con normalidad el habla y el lenguaje, lo que se constituye en la base para muchos de los aprendizajes posteriores. Las alteraciones en la audición pueden causar, a cualquier edad, problemas de comunicación para un niño ${ }^{1}$, los cuales pueden provocar sentimientos de ira, estrés, soledad y baja autoestima, además, si se amplía el contexto, la pérdida de audición no tratada afecta el desarrollo social y económico de los países.

La hipoacusia es la incapacidad parcial o total para escuchar sonidos en uno o en ambos oídos; la gravedad de la lesión dependerá de tres factores principales: intensidad de la pérdida auditiva, la localización de la lesión y el momento de aparición de esta ${ }^{2}$.

La infección congénita por el virus zika (VZ) se ha relacionado con microcefalia, defectos del sistema nervioso central, lesiones oculares y ortopédicas, además de alteraciones neurológicas, de neurodesarrollo y auditivas ${ }^{3-5}$.

El 17 de noviembre del 2015, Brasil reportó la confirmación de la presencia del VZ en muestras de líquido amniótico de dos mujeres embarazadas que mostraban fetos con microcefalia, ambas habían presentado síntomas de infección por el VZ durante su embarazo, a partir de ese momento se emite una alerta epidemiológica a través de la Organización Mundial de la Salud (OMS), advirtiendo sobre el aumento de los casos de microcefalia ${ }^{6}$.

En Costa Rica, a partir de enero de 2016, se confirmó la circulación autóctona de la infección, cuando se detectó el primer caso en un turista estadounidense, que se infectó en el país durante su estancia entre el 19 al 26 de diciembre de 2015 y fue diagnosticado a su regreso a Massachusetts, Estados Unidos ${ }^{7}$. En febrero de 2016 se detectaron varios casos autóctonos de la enfermedad confirmados por laboratorio, en Guanacaste y de esta provincia, el virus se diseminó a todas las regiones del país ${ }^{8}$.

Desde que se inició el brote de la enfermedad causada por el virus de zika en Costa Rica, a finales del 2015 e inicios de 2016, se ha generado un gran interés debido a su asociación con la aparición de manifestaciones tanto neurológicas como de malformaciones del desarrollo fetal en las mujeres infectadas durante el embarazo. El Boletín Epidemiológico 01-2018 del Ministerio de Salud de Costa Rica $(\mathrm{MS})^{9}$, indica que en el 2017 se notificaron 2414 casos, de los cuales se confirmaron por laboratorio 359 casos de zika, cero síndromes neurológicos, 90 embarazadas positivas y 7 casos de síndrome congénito y o microcefalia asociados al virus del zika. De momento, Costa Rica no contabiliza muertes relacionadas con este virus.

Costa Rica es un país con zonas de alta densidad del vector transmisor del VZ, por este motivo, el MS conformó una Comisión de expertos del área de Vigilancia Epidemiológica del Ministerio de Salud, el Centro de Registro de Enfermedades Congénitas (CREC) y el Centro Nacional de Referencia de Virología del INCIENSA y la CCSS para la elaboración, implementación y seguimiento del "Protocolo de vigilancia de microcefalia probablemente asociado a zika en Costa Rica". La primera versión fue publicada y diseminada a los servicios de salud en abril de 2016.

Seguidamente, ante la evidencia de otros defectos congénitos asociados al VZ, una segunda y tercera versión de dicho Protocolo se publicaron en diciembre de 2016 y marzo de 2018 respectivamente ${ }^{10}$. En este documento se brindan 
los lineamientos para el diseño e implementación de acciones orientadas a la vigilancia de microcefalia y otros defectos congénitos que se han asociado con el síndrome congénito causado por la infección por VZ. Dichos lineamientos se dirigen a los responsables de la atención de los recién nacidos en los servicios de salud de la CCSS y los servicios a nivel privado, así como a los encargados de implementar la vigilancia de la salud pública en los diferentes niveles de atención.

Según la evidencia científica de las malformaciones y anomalías en el neurodesarrollo del recién nacido adquiridas por el VZ, se estima conveniente brindar seguimiento diferenciado no solo a los recién nacidos con microcefalia, sino también a aquellos con síndrome congénito posiblemente asociado al virus de zika, y a los niños con infección vertical documentada que son normocéfalos y clínicamente asintomáticos al momento del nacimiento, ya que las manifestaciones clínicas y alteraciones del desarrollo pueden ser de aparición tardía postnatal al tratarse de una infección gestacional por el VZ durante el último trimestre del embarazo ${ }^{11}$.

El principal objetivo de este artículo consiste en definir la evaluación audiológica idónea que deben tener los niños hijos de madre con exposición al VZ durante la etapa prenatal, o sospecha de una infección congénita por el VZ de acuerdo con la evidencia existente en la literatura, para contribuir en el diagnóstico temprano de la pérdida de audición causada por este virus, así como su seguimiento exhaustivo desde un punto de vista audiológico.

\section{Materiales y métodos}

Se realizó un estudio de revisión bibliográfica cualitativa basado en la búsqueda bibliográfica entre junio del 2019 y junio del 2020 en las bases de datos Redalyc, Pubmed, y Scielo, utilizando como descriptores las palabras Hearing loss AND zika, congenital zika OR zika Virus; se seleccionaron artículos publicados del 2016 al 2020, en idiomas español, inglés y portugués. La selección de artículos, la extracción de datos y la evaluación de la calidad fueron realizadas por dos revisores independientes. Se incluyeron estudios sobre la evaluación auditiva de pacientes con infección por el VZ congénita o adquirida; y / o hipótesis o evidencias sobre la fisiopatología del deterioro auditivo asociado con el VZ; y / o recomendaciones sobre detección y seguimiento de pacientes con deterioro auditivo por el VZ. Se incluyeron 37 artículos científicos publicados como series de casos y artículos de revisión, así como guías clínicas publicados de 2016 al 2020, en idiomas español, inglés y portugués. Por último, se utilizaron doce capítulos de libros relacionados con la valoración audiológica en recién nacidos y cuatro lineamientos o protocolos publicados en la web para un total de 51 referencias bibliográficas.

Basados en la evidencia, se propusieron algoritmos de evaluación en los niños hijos de madres con exposición al virus de zika durante la etapa prenatal o sospecha de infección congénita.

La figura 1, resume el diagrama de flujo de selección de los artículos y extracción de la información.

\section{Discusión de resultados}

En general y basándose en la evidencia, la infección por el VZ podría presentar un inicio tardío y fluctuación o progresión de la pérdida auditiva, por lo que se requiere un seguimiento del niño por un tiempo prolongado mientras el infante adquiere todas las habilidades necesarias para el lenguaje y la comunicación. A pesar de que se encontró 
poca información publicada sobre la evaluación e intervención audiológica en esta población, se lograron identificar los principales procesos fisiopatológicos propios del VZ en el sistema auditivo del embrión y feto, así como las malformaciones craneales y afectaciones de la corteza y del sistema nervioso, además de los patrones derivados de la evaluación audiológica.
Con base en la literatura publicada a la fecha, se proponen los algoritmos de evaluación audiológica idónea que deben tener los hijos de madres con exposición al VZ durante la etapa prenatal o sospecha de infección congénita por el virus. A continuación, se resume la evidencia que apoya el seguimiento audiológico de esta población por un tiempo prolongado.

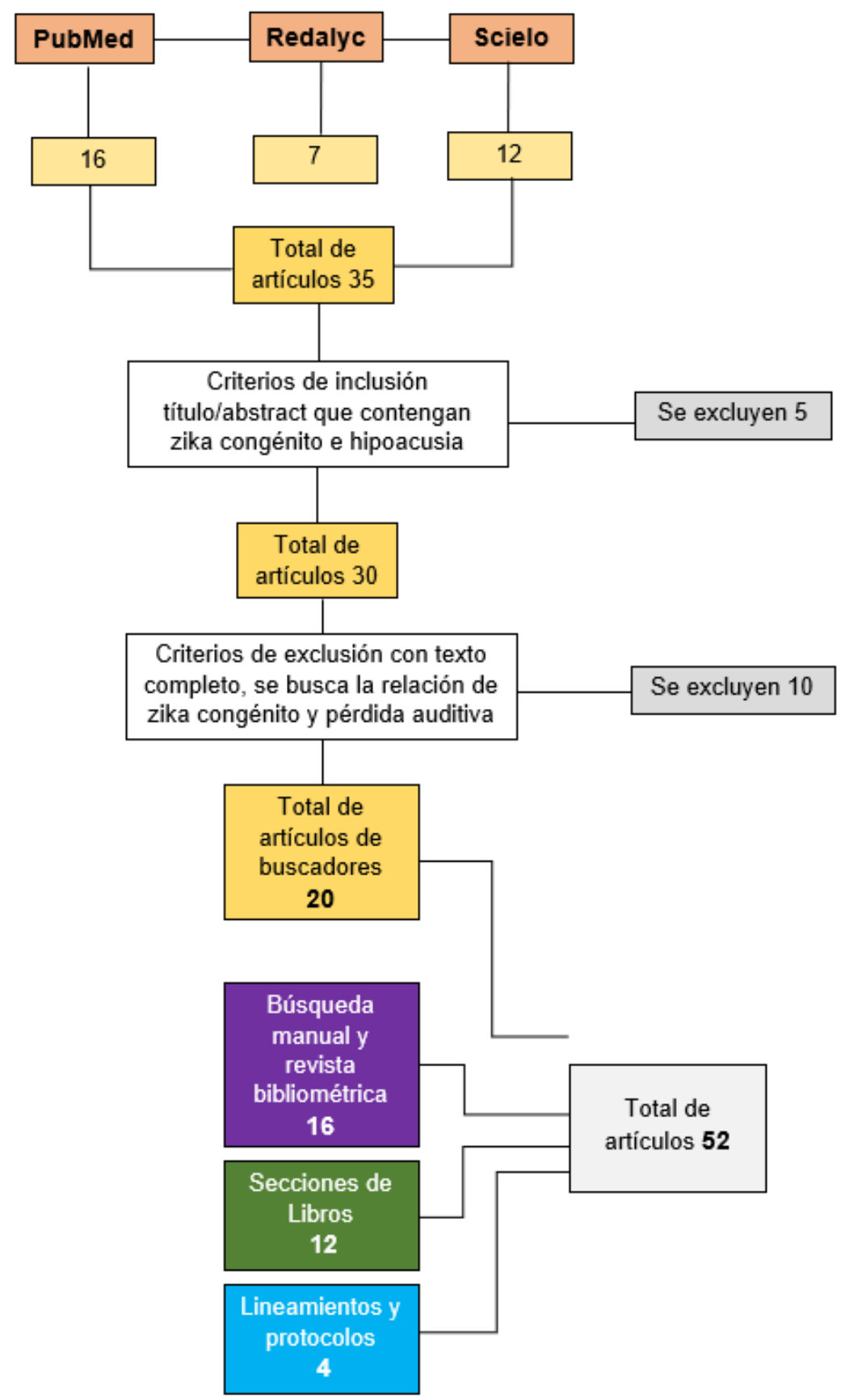

Figura 1. Algoritmo de búsqueda y selección de estudios, así como extracción de la información.

Fuente: Elaboración propia de las autoras. 
Efectos del virus de zika en la audición del feto y recién nacido

La hipoacusia central ha sido descrita en varias series de casos como parte de las manifestaciones frecuentes en el síndrome de zika congénito ${ }^{3}$. La hipoacusia neurosensorial retrococlear o hipoacusia central es la ausencia del nervio auditivo, lesión de este último o de vías auditivas. Estas sorderas son generalmente profundas, permanentes e irreversibles, dado que el nervio auditivo no puede enviar información al cerebro. De acuerdo con la evidencia publicada a la fecha, la prevalencia de sordera neurosensorial diagnosticada por potenciales evocado de tallo cerebral ha sido estimada en alrededor del $6 \%{ }^{12}$.

Barbossa et $\mathrm{al}^{13}$, indican que la pérdida auditiva neurosensorial debe de considerarse parte del espectro de hallazgos clínicos asociados con la infección congénita por el VZ, y que dicha infección se debe calificar como un factor de riesgo para la pérdida auditiva en los programas de detección auditiva, además, sugieren que los niños con evidencia de infección congénita por el VZ, que se someten a pruebas de detección inicialmente normales, deben recibir un seguimiento regular. En su artículo publicado en el 2019 en el cual hace una revisión de la evidencia existente a la fecha, afirma que hasta un $6 \%$ de los niños afectados con microcefalia debido al zika congénito, sufrían de pérdida auditiva, lo que obliga a considerar este virus como un factor de riesgo para desarrollar esta patología.

En Costa Rica, un estudio de serie de casos que describe el brote de zika congénito entre marzo 2016 y marzo 2018 reportó un 13\% de hipoacusia neurosensorial en niños con zika congénito, todos diagnosticados por la prueba de Potenciales Evocados Auditivos Automatizados (PEAA) ${ }^{14}$.
Por otra parte, se han realizado investigaciones en donde se compara la pérdida auditiva debidoal VZ con otras infecciones congénitas como la toxoplasmosis, el citomegalovirus y demás infecciones del grupo TORCHS. En la Tabla 1 se resume el tipo de pérdida auditiva causada por infecciones congénitas y su incidencia.

De acuerdo con lo anterior se puede predecir que no es infrecuente que los niños infectados prenatalmente a través de transmisión vertical mostrarán limitaciones en sus capacidades auditivas, aun cuando se presenten pruebas audiológicas que evalúan el sistema auditivo periférico sin alteraciones.

En cuanto al mecanismo de lesión, los estudios pioneros han identificado el tropismo del virus del sistema nervioso central en fetos infectados, con consecuencias devastadoras para el desarrollo, incluyendo malformaciones graves del sistema nervioso central ${ }^{18}$. Por lo tanto, también es importante dilucidar mejor la patogénesis de la afectación del sistema auditivo, tanto en infecciones congénitas como adquiridas, de manera que se puedan desarrollar estrategias preventivas, terapéuticas, de detección o de seguimiento.

La hipoacusia neurosensorial causada por el VZ podría existir por una vía inflamatoria, ya que el virus podría tener acceso dentro de la cóclea a través de las estructuras del acueducto coclear, no obstante, aún no hay claridad sobre el sitio exacto de la lesión. Sin embargo, Carney et $\mathrm{al}^{19}$, sugieren que en algunos casos no se visualiza ninguna lesión de las estructuras del oído interno, pero se ha encontrado un deterioro auditivo en el tronco encefálico o a nivel cortical. 
Tabla 1. Características de la hipoacusia causada por virus de transmisión perinatal en el ser humano

\begin{tabular}{|c|c|c|c|c|}
\hline Virus & $\begin{array}{c}\text { Tipo de pérdida de } \\
\text { audición }\end{array}$ & $\begin{array}{c}\text { Grado de la pérdida } \\
\text { auditiva }\end{array}$ & Incidencia & Audición \\
\hline Citomegalovirus & $\begin{array}{l}\text { Hipoacusia } \\
\text { neurosensorial } \\
\text { progresiva }\end{array}$ & Severa & $\begin{array}{c}6-23 \% \text { madres } \\
\text { asintomáticas } 25-65 \% \\
\text { madres sintomáticas }\end{array}$ & No se recupera \\
\hline Rubeóla & $\begin{array}{c}\text { Hipoacusia } \\
\text { neurosensorial bilateral }\end{array}$ & Leve a severa & $12-19 \%$ & No se recupera \\
\hline Herpes simple & $\begin{array}{c}\text { Hipoacusia } \\
\text { neurosensorial unilateral } \\
\text { o bilateral }\end{array}$ & Moderada a profunda & $27-34 \%$ & No se recupera \\
\hline Varicela Zóster & $\begin{array}{c}\text { Hipoacusia } \\
\text { neurosensorial unilateral } \\
\text { o bilateral }\end{array}$ & $\begin{array}{l}\text { Bilateral: Profunda } \\
\text { Unilateral: Leve a } \\
\text { Moderada }\end{array}$ & $1-3,4 \%$ & $\begin{array}{l}\text { Dependiendo del grado de } \\
\text { pérdida Auditiva }\end{array}$ \\
\hline Paperas & $\begin{array}{c}\text { Hipoacusia } \\
\text { neurosensorial unilateral }\end{array}$ & Variable & $0,5-3,4 \%$ & Completa o parcial \\
\hline $\begin{array}{l}\text { Virus del Nilo del } \\
\text { oeste }\end{array}$ & $\begin{array}{c}\text { Hipoacusia } \\
\text { neurosensorial bilateral }\end{array}$ & Leve a profunda & $0,01-5 \%$ & No se recupera \\
\hline Zika & $\begin{array}{c}\text { Hipoacusia } \\
\text { neurosensorial bilateral }\end{array}$ & Leve a profundo & $0 \%-29 \%$ & No se recupera \\
\hline Toxoplasmosis & $\begin{array}{c}\text { Hipoacusia } \\
\text { neurosensorial bilateral }\end{array}$ & Moderada a profunda & $5 \%-50 \%$ & No se recupera \\
\hline Sífilis tardía & $\begin{array}{c}\text { Hipoacusia } \\
\text { neurosensorial bilateral }\end{array}$ & Leve a profunda & $25 \%-38 \%$ & No se recupera \\
\hline
\end{tabular}

Fuente: modificación realizada por las autoras basadas en Leite et al ${ }^{15}$, Franca et al $^{16}$, Voordouw et al ${ }^{17}$.

En la Tabla 2 se resumen las principales hipótesis definidas por los autores más relevantes sobre la patogénesis de la pérdida auditiva en la infección congénita por el VZ. Las principales teorías apuntan a un daño al nervio auditivo y a la cóclea, ya sea causado por efecto directo del virus o un proceso inmunológico en respuesta a este.
En el estudio realizado por Mittal et $\mathrm{al}^{20}$, se concluye que la infección por el VZ podría presentar un inicio tardío, fluctuación o progresión de la pérdida auditiva, por lo que se requiere hacer un seguimiento del niño por un tiempo prolongado. Este estudio incluyó solamente a niños que presentan microcefalia, lo que deja abierta la posibilidad de que 
el espectro de afectación de la infección congénita por el VZ abarque niños sin microcefalia, pero con déficits auditivos, como ocurre en la rubéola congénita y las infecciones por el citomegalovirus, donde los niños que nacen sin aparente anomalía estructural pueden tener pérdida auditiva al nacer o esta se presenta posteriormente.

\section{Patrones de presentación de la hipoacusia desde el punto de vista audiológico}

Como se comentó anteriormente, se ha podido demostrar que los niños que han sido expuestos prenatalmente al VZ presentan una afectación en su sistema auditivo que puede ser progresiva, de presentación tardía y puede afectar uno o ambos oídos.

\section{Tabla 2. Consideraciones sobre la patogénesis del daño auditivo congénito causado por el virus de Zika según autores}

\begin{tabular}{|c|c|}
\hline Autor (año) País & Hipótesis sobre la patogénesis \\
\hline Leal (2016) Brasil & $\begin{array}{l}\text { En la mayoría de los casos de pérdida auditiva asociada con infección viral congénita, el daño se localiza } \\
\text { dentro de la cóclea. Sin embargo, no se puede descartar un origen central. }\end{array}$ \\
\hline Leal (2016) Brasil & $\begin{array}{l}\text { Todavía es incierto si los daños en los tejidos causados por la infección intrauterina por el VZ son una } \\
\text { expresión de un efecto directo del virus en sí o de una reacción inmune del huésped. }\end{array}$ \\
\hline Vinhaes (2017) Brasil & $\begin{array}{l}\text { El mecanismo de la hipoacusia neurosensorial asociado con una infección viral aguda implica daño del oído } \\
\text { interno o del nervio auditivo, por un efecto viral directo o mediado por un proceso autoinmune. }\end{array}$ \\
\hline $\begin{array}{l}\text { Mittal (2017) Estados } \\
\text { Unidos }\end{array}$ & $\begin{array}{l}\text { La exposición al VZ está asociada con pérdida auditiva como resultado del daño al oído interno o al nervio } \\
\text { auditivo por un efecto viral directo o medida por un proceso autoinmune, como se demuestra en el caso de } \\
\text { otras infecciones virales. }\end{array}$ \\
\hline Borja (2017) Brasil & $\begin{array}{l}\text { En este estudio se observaron latencias absolutas más tempranas en niños con microcefalia, con estímulos } \\
\text { de alta intensidad para la investigación de la integridad neurofisiológica del tallo cerebral. Considerando el } \\
\text { tropismo del zika para el tejido nervioso, es posible que la neuroconducción del estímulo acústico en niños } \\
\text { expuestos al virus y con microcefalia, sea diferente a la de otros niños, incluso aquellos expuestos a otras } \\
\text { infecciones congénitas. }\end{array}$ \\
\hline & $\begin{array}{l}\text { Un tema aún no aclarado es la topografía de la lesión responsable de la hipoacusia producida por la infección } \\
\text { por el VZ. Ninguno de estos niños presentaba anomalías anatómicas del oído interno en los exámenes } \\
\text { por imágenes, pero es bien sabido, que otras infecciones congénitas pueden causar sordera sin ninguna } \\
\text { malformación coclear; por lo tanto, no es posible descartar una pérdida auditiva sensorial en estos casos. }\end{array}$ \\
\hline Leal (2019) Brasil & $\begin{array}{l}\text { Los cambios del sistema nervioso central en los recién nacidos demuestran afecciones que involucran las } \\
\text { vías auditivas como resultado de la reacción inflamatoria del tejido. }\end{array}$ \\
\hline Martínez (2017) Brasil & $\begin{array}{l}\text { La función de la cóclea es normal, sin embargo, se presentan cambios en la sincronía neural que se puede } \\
\text { clasificar como neuropatía. }\end{array}$ \\
\hline $\begin{array}{l}\text { Marquez Abramov } \\
\text { (2018) Brasil }\end{array}$ & $\begin{array}{l}\text { Decir que hay normalidad en el tronco encefálico es desafiante, teniendo en cuenta la interrupción sustancial } \\
\text { del desarrollo del cerebro, así como la evidencia que sugiere la acción del virus en la célula progenitora } \\
\text { desde la fase de proliferación celular. Aunque el tronco encefálico se desarrolla en paralelo con el telencéfalo } \\
\text { durante las primeras etapas de la embriogénesis, el desarrollo del tallo cerebral no exhibe los mismos } \\
\text { procesos de migración neuronal observados en el telencéfalo, lo que sugiere que el ZV actúa principalmente } \\
\text { sobre mecanismos específicos de formación de corteza cerebral que se extienden desde el primer al tercer } \\
\text { trimestre. }\end{array}$ \\
\hline
\end{tabular}

Fuente: modificación de las autoras basadas en Magalhaes Barbosa et al ${ }^{18}$. 
Tabla 3. Pruebas de evaluación auditiva utilizadas en la valoración hipoacusia en niños con infección congénita por el virus zika

\begin{tabular}{|c|c|c|c|c|c|c|}
\hline Autor/Año & País & Muestra & $\begin{array}{l}\text { Microcefalia/cambio } \\
\text { neurológico }\end{array}$ & Zika positivo & $\begin{array}{l}\text { Edad en la } \\
\text { evaluación } \\
\text { auditiva }\end{array}$ & $\begin{array}{c}\text { Pruebas de evaluación } \\
\text { auditiva }\end{array}$ \\
\hline Leal et al., 2016 & Brasil & 1 & Microcefalia & Sí & Recién nacido & $\begin{array}{c}\text { EOA+PEAA+PEATC+ } \\
\text { observación de la } \\
\text { conducta }\end{array}$ \\
\hline Leal et al., 2016 & Brasil & 70 & Microcefalia y zika & Sí & $\begin{array}{l}\text { I prueba: } 97 \text { días } \\
\text { II prueba: } 127 \text { días }\end{array}$ & $\begin{array}{l}\text { I test PEAA: refieren } 16 \\
\text { niños o niñas de } 70 \text { niños } \\
\text { o niñas evaluados } \\
\\
5 \text { con microcefalia } \\
\text { severa e hipoacusia } \\
\text { neurosensorial y dos con } \\
\text { hipoacusia conductiva. } \\
\\
\text { II test PEAA refieren } 8 \\
\text { niños o niñas de } 16 \text { niños } \\
\text { o niñas evaluados }\end{array}$ \\
\hline $\begin{array}{c}\text { Grupo de } \\
\text { Investigación } \\
\text { en Epidemia de } \\
\text { Microcefalia, } \\
2016\end{array}$ & Brasil & 104 & $\begin{array}{l}\text { Microcefalia, } 10 \\
\text { pretérmino }\end{array}$ & No determina & $\begin{array}{c}\text { No hay } \\
\text { información }\end{array}$ & EOA \\
\hline $\begin{array}{l}\text { Vander Linden } \\
\text { et al.,2016 }\end{array}$ & Brasil & 15 & $\begin{array}{l}\text { Microcefalia, } 2 \\
\text { pretérmino }\end{array}$ & Sí & $\begin{array}{c}\text { No hay } \\
\text { información }\end{array}$ & PEAA \\
\hline $\begin{array}{c}\text { Besnard et al. } \\
2016\end{array}$ & $\begin{array}{l}\text { Francia } \\
\text { Polinesia }\end{array}$ & 19 & $\begin{array}{c}11 \text { abortos } \\
19 \text { malformaciones } \\
2 \text { prematuros }\end{array}$ & Sí & $\begin{array}{c}\text { No hay } \\
\text { información }\end{array}$ & No especifica evaluación \\
\hline $\begin{array}{l}\text { Borja et al. } \\
\quad 2016\end{array}$ & Brasil & 76 & $\begin{array}{c}46 \text { con } \\
\text { malformaciones }\end{array}$ & No determina & 86 días & EOA \\
\hline $\begin{array}{c}\text { Nogueira et al, } \\
2017\end{array}$ & Brasil & 54 & 0 & Sí & $\begin{array}{c}\text { No hay } \\
\text { información }\end{array}$ & EOA+PEATC \\
\hline $\begin{array}{l}\text { Satterfield- } \\
\text { Nashet al., } \\
\quad 2017\end{array}$ & Brasil & 19 & 19 & Sí & 19-24 meses & Juguetes sonoros \\
\hline Silva et al. 2017 & Brasil & 24 & Microcefalia & $\begin{array}{l}\text { No hay } \\
\text { información }\end{array}$ & $1-12$ meses & EOA+PEATC \\
\hline $\begin{array}{c}\text { Marques } \\
\text { Abramovet al., } \\
2018\end{array}$ & Brasil & 19 & Microcefalia & Sí & $12-62$ semanas & PEATC \\
\hline
\end{tabular}

EOA: Emisiones Otoacústicas; PEAA: Potenciales Evocados Automatizados; PEATC: Potenciales Evocados de Tallo Cerebral

Fuente: traducción autoras basado en Magalhaes Barbosa et al ${ }^{18}$. 
Tabla 4. Comparación de protocolos de evaluación auditiva para niños afectados con zika congénito según pruebas realizada en diferentes países entre 2016 y 2020

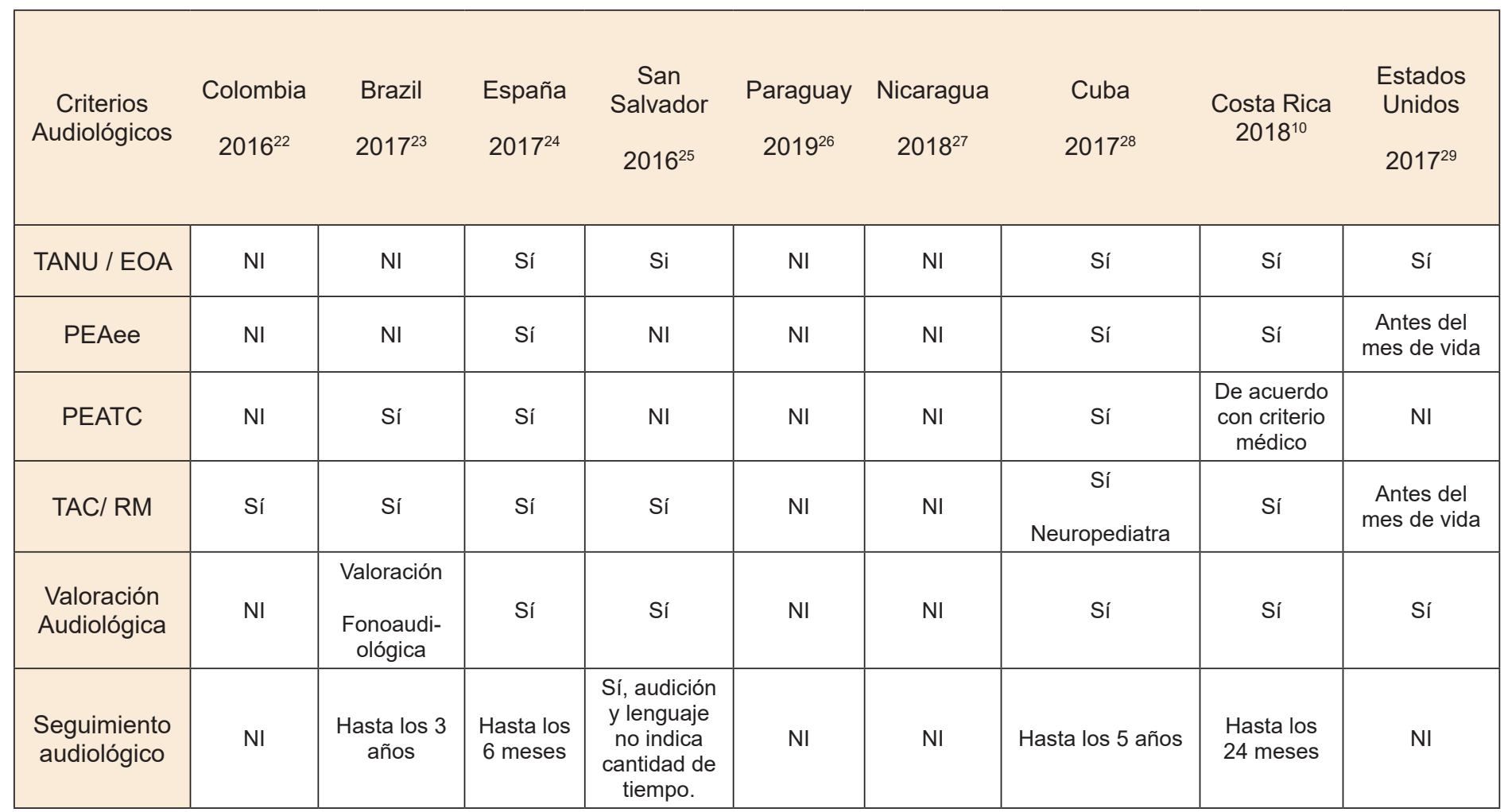

EOA: Emisiones Otoacústicas, NI: No indica,PEAA: Potenciales Evocados Automátizados, PEATC: Potenciales Evocados de Tallo Cerebral, RM: Resonancia magnética, TAC: Tomografía Axial Computarizada, TANU: Tamizaje auditivo neonatal Universal

Fuente: Elaboración propia basada en referencias ${ }^{(10,22-29)}$.

En un estudio realizado por Adebanjo et $\mathrm{al}^{21}$, en Estados en 2016, se indica que se deben de incluir dentro de los exámenes auditivos, tanto las Emisiones Otoacústicas (EOA), como los PEAA, dado que la infección por el VZ puede causar pérdida auditiva progresiva o de inicio tardío en los bebés, así como neuropatía auditiva.

En la Tabla 3 se presenta un resumen de los diversos estudios realizados por los autores con el fin de detectar las pérdidas auditivas en los casos de infección congénita por el virus de zika.

\section{Protocolos internacionales de evaluación} auditiva en infantes expuestos prenatalmente al virus de zika

Los protocolos de evaluación de la audición en infantes expuestos prenatalmente al virus de zika son escasos y varían de país en país, dependiendo de sus recursos y organización del sistema de salud. En general, no se encontró un protocolo específico de evaluación auditiva, sino que el mismo está inmerso dentro de la evaluación integral del niño y carece de especificidad. La Tabla 4, presenta la descripción comparativa entre los diferentes protocolos de evaluación realizados a los niños nacidos de madres con el VZ, en los diferentes países que han publicado esos protocolos. 


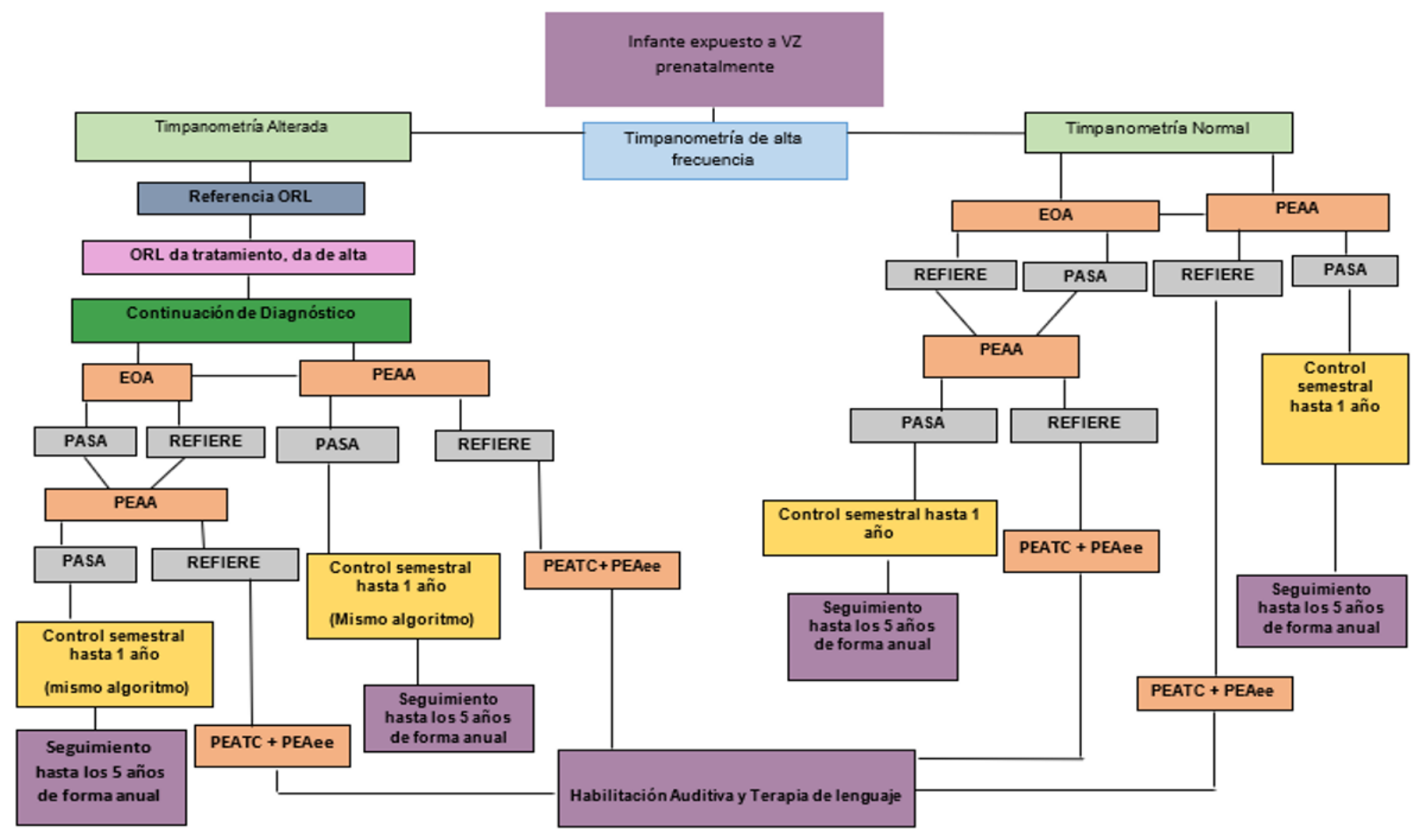

Figura 2. Algoritmo de evaluación auditiva de niños con exposición prenatal al virus de zika

EOA: Emisiones Otoacústicas PEAA: Potenciales Evocados Automatizados. PEATC: Potenciales Evocados de Tallo Cerebral. PEAee: Potenciales Evocados Auditivos de estado estable.

Fuente: elaboración de las autoras

\section{Propuesta de algoritmo de evaluación}

\section{audiológica en niños de madres que}

presentaron el virus de zika durante el

embarazo.

Como se comentó anteriormente, las pruebas electrofisiológicas son necesarias para detectar un daño en el sistema nervioso central relacionado con el VZ, las cuales podrían presentarse desde el nacimiento o, por el contrario, podría darse una pérdida auditiva fluctuante o progresiva que se manifieste en los primeros años de vida. De aquí la importancia de proponer y hacer más robusto un algoritmo de la evaluación audiológica en niños cuyas madres sufrieron el VZ en el embarazo, con el principal objetivo de alcanzar un diagnóstico temprano, así como una intervención oportuna, con lo que se pueda lograr una adecuada rehabilitación de manera multidisciplinaria.

Los profesionales que establezcan el primer contacto con el neonato que se expuso a la infección por el VZ en etapa prenatal, deben referirlos a una evaluación auditiva periódica aun cuando no se presente una pérdida auditiva al nacer ${ }^{12}$. Las Figuras 2 a 4 presentan una propuesta de algoritmo de evaluación audiológica en niños de madres que tuvieron infección por el virus de zika durante el embarazo, fundamentada en los hallazgos derivados de este estudio de revisión.

Esta propuesta de detección y seguimiento consta de tres algoritmos: 
- Evaluación al neonato expuesto al virus de zika durante el embarazo (madre que tuvo zika durante el embarazo o bien tiene prueba de laboratorio positiva para el virus de zika en su etapa de recién nacido temprano) (Figura 2).

- Seguimiento de recién nacidos sin compromiso cognitivo (Figura 3).
- Seguimiento de recién nacidos con compromiso cognitivo (Figura 4).

Este estudio tiene la limitación de que se basa en artículos descriptivos en su mayoría y se encontró poca información publicada sobre la evaluación e intervención audiológica en esta población.

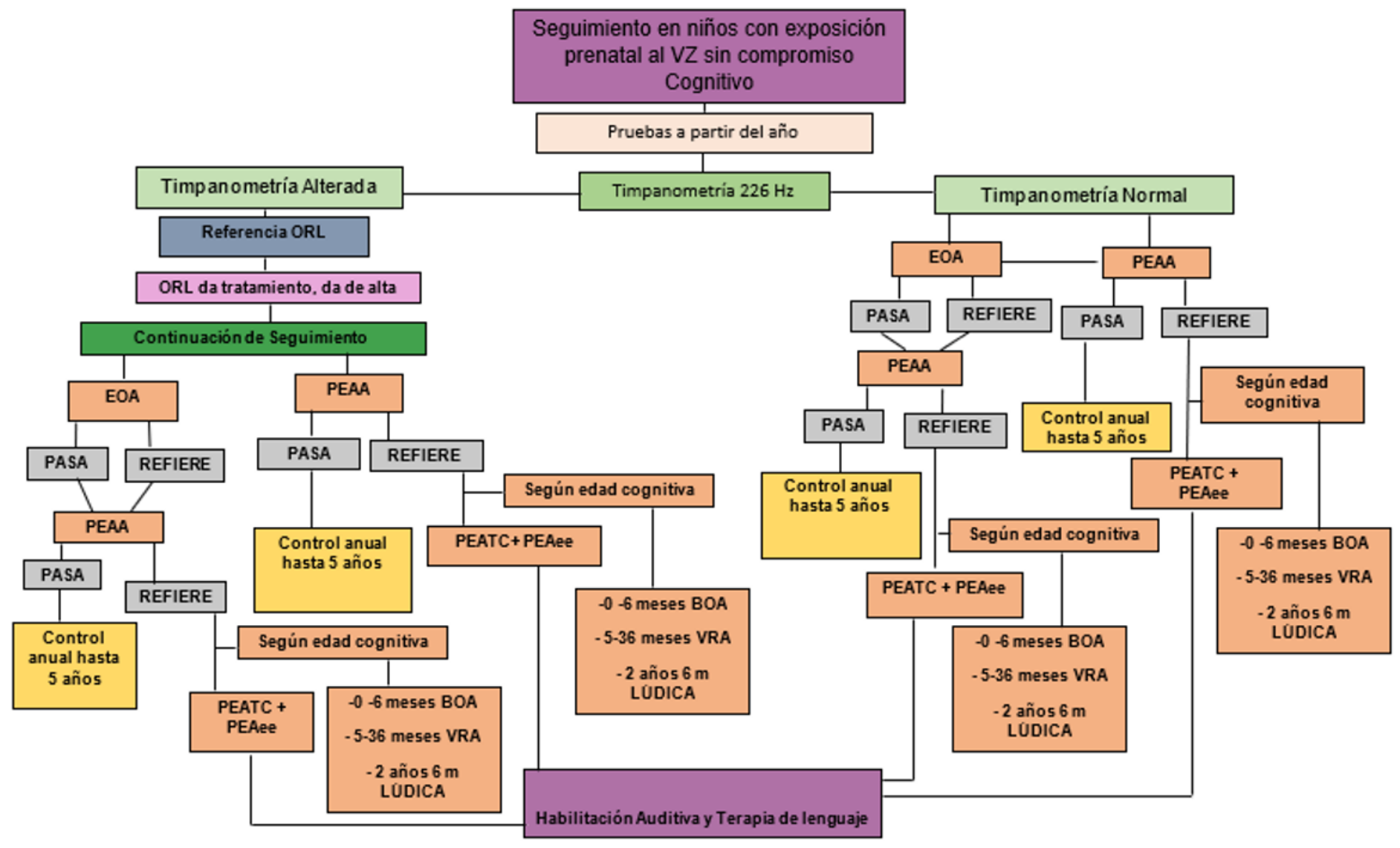

Figura 3. Seguimiento de evaluación audiológica en niños con exposición prenatal al virus zika sin compromiso cognitivo

BOA: Audiometría por Observación de la conducta; EOA: Emisiones Otoacústicas; PEAA: Potenciales Evocados Automatizados; PEAee: Potenciales Evocados Auditivos de estado estable; PEATC: Potenciales Evocados de Tallo Cerebral; VRA: Audiometría por reforzamiento visual.

Fuente: elaboración de las autoras. 


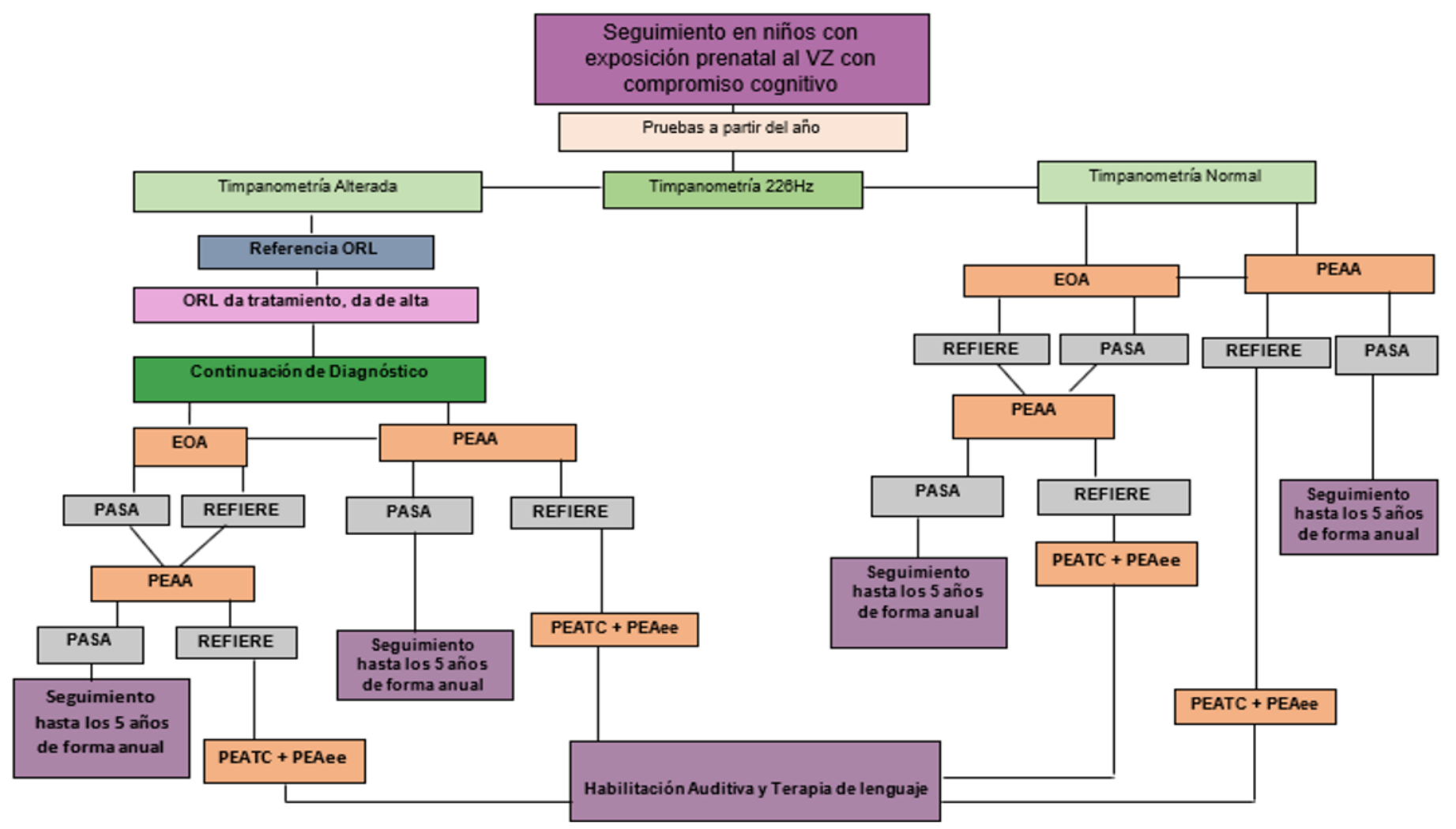

\section{Figura 4. Seguimiento de evaluación audiológica en niños con exposición prenatal al virus zika con compromiso cognitivo}

EOA: Emisiones Otoacústicas; PEAA: Potenciales Evocados Automatizados; PEAee: Potenciales Evocados Auditivos de estado estable; PEATC: Potenciales Evocados de Tallo Cerebral.

Fuente: Elaboración de las autoras.

\section{Conclusiones}

En los niños o niñas con el virus del zika se ha encontrado un deterioro auditivo por afectación tanto a nivel de vía auditiva como a nivel coclear, así mismo, estos pueden presentar alteraciones del sistema nervioso central como microcalcificaciones intracraneales (principalmente corticales y subcorticales), hipoplasia cerebral o cerebelar, agenesia del cuerpo calloso, alteraciones de los ventrículos cerebrales, anormalidades de la fosa posterior; todas las cuales serían los causantes de una posible hipoacusia central. La infección por el VZ podría mostrar un inicio tardío, fluctuación o progresión de la pérdida auditiva, por lo que se requiere un seguimiento del niño por un tiempo prolongado mientras el infante adquiere todas las habilidades necesarias para el lenguaje y la comunicación. Así pues, la valoración audiológica de los niños hijos de madres afectadas por este virus durante el embarazo, no solo debe ser oportuna y continua durante sus primeros años, sino que debe ir de la mano con la valoración interdisciplinaria de varios profesionales como radiólogos, otorrinolaringólogos, neurólogos e infectólogos, entre otros, con el fin de brindar al niño un abordaje y una rehabilitación integral para el mejor desarrollo posible de sus habilidades, por otra 
parte, es importante que los profesionales de salud estén conscientes del impacto que el virus de zika puede provocar en la audición de los niños y en su neurodesarrollo.

Hay que enfatizar, ante las autoridades de salud del país, la importancia de la afectación auditiva que puede tener el VZ en la población infantil, de manera que se pueda elaborar una herramienta que permita tanto el diagnóstico como conocer el impacto de esta problemática con la integración de datos a nivel nacional, su seguimiento audiológico y la respectiva comprobación de los avances realizados según el algoritmo presentado.

\section{Referencias Bibliográficas}

1. Teruel J. Intervención en niños/as con deficiencia auditiva y la sordera. En: Latorre A. Trastornos y dificultades del desarrollo: Evaluación, intervención y casos prácticos. Valencia: Universidad de Valencia; 2010. 83-124.

2. Sedano C, San Martin A, Rahal E. Realidad nacional de los programas de detección auditiva temprana con miras a la cobertura universal. Rev Otorrinolaringol Cir Cabeza Cuello. 2018;78(1):914. doi: 10.4067/s0717-75262018000100009.

3. Moore CA, Staples JE, Dobyns WB, Pessoa A, Ventura CV, Fonseca EB, et al. Congenital Zika Syndrome: Characterizing the Pattern of Anomalies for Pediatric Healthcare Providers. JAMA Pediatr. 2017;171(3):288-295. doi: 10.1001/jamapediatrics.2016.3982.

4. Mocelin H, Prado TN, Freitas PSS, Bertolde Al, Perez F, Riley LW, et al. Variação na detecção da síndrome congênita do Zika em função de alterações em protocolos. Rev Panam Salud Publica. 2019;43:e79. doi: 10.26633/RPSP.2019.79.

5. Escosteguy CC, Escosteguy Medronho R, Rodrigues RC, da Silva LDR, de Oliveira BA, Ma- chado FB, et al. Microcefalia e alterações do sistema nervoso central relacionadas à infecção congênita pelo vírus Zika e outras etiologias infecciosas en estado do Rio de Janeiro: estudio transversal, 2015 a 2017. Rev Panam Salud Publica. 2020;44:e151. doi: 10.26633/RPSP.2020.151.

6. Organización Panamericana de la Salud. Alerta Epidemiológica Incremento de microcefalia en el nordeste de Brasil [Internet]. OPS; 2015. Disponible en: https://www.paho.org/es/file/42056/ download?token=Rdo2CFhc

7. Chen LH. Zika Virus Infection in a Massachusetts Resident After Travel to Costa Rica: A Case Report. Ann Intern Med. 2016;164(8):574-6. doi: 10.7326/L16-0075.

8. Ávalos Á. Embarazada se convierte en primer caso autóctono de zika en Costa Rica [Internet]. La Nación. 22 de febrero de 2016. Disponible en: https://www.nacion.com/el-pais/salud/embarazada-se-convierte-en-primer-caso-autoctono-de-zika-en-costa-rica/PSI4Z6V75ZGARLKBA62NAH6INA/story/.

9. Ministerio de Salud (CR). Resumen Dengue Zika y Chikungunya, Costa Rica SE 1-40, 2018. Boletín epidemiológico $N^{\circ}$ 22-2018. Enfermedades transmitidas por vectores [Internet]. San José: Ministerio de Salud; 2018. Disponible en: https:// www.ministeriodesalud.go.cr/index.php/vigilancia-de-la-salud/boletines/enfermedades-de-transmision-vectorial-2017-1/3938-pdf-boletin-epidemiologico-no-22-2018-zika-chikungunya-y-dengue/file

10. Ministerio de Salud (CR), Instituto Costarricense de Investigación y Enseñanza en Nutrición y Salud, Caja Costarricense de Seguro Social. Protocolo de Vigilancia de microcefalia y síndrome congénito asociado a virus del zika en Costa Rica [Internet]. San José: Ministerio de Salud; 2018. Disponible en: https://www.ministeriodesalud.go.cr/index.php/ vigilancia-de-la-salud/normas-protocolos-y-guias/ 
malformaciones-congenitas/3786-protocolo-vigilancia-zika-congenito-microcefalia-marzo-2018/file

11. Ministerio de Salud (CR). Protocolo de Atención, Caracterización del Fenotipo y seguimiento del neurodesarrollo y secuelas en niños afectados con embriofetopatía por virus del Zika en Costa Rica. San José: Caja Costarricense del Seguro Social; 2018

12. Leal MC, Muniz LF, Ferreira TS, Santos CM, Almeida LC, Van Der Linden V, et al. Hearing Loss in Infants with Microcephaly and Evidence of Congenital Zika Virus Infection - Brazil, November 2015-May 2016. MMWR Morb Mortal Wkly Rep. 2016;65(34):917-9. doi: 10.15585/mmwr. $\mathrm{mm} 6534 \mathrm{e} 3$.

13. Barbosa MHM, Magalhães-Barbosa $M C$, Robaina JR, Prata-Barbosa A, Lima MAMT, Cunha AJLAD. Auditory findings associated with Zika virus infection: an integrative review. Braz J Otorhinolaryngol. 2019;85(5):642-663. doi: 10.1016/j. bjorl.2019.05.002.

14. Benavides-Lara A, Barboza-Arguello MP, González-Elizondo $M$, Hernández-deMezerville $M$, Brenes-Chacón H, Ramírez-Rojas $M$, et al. Zika Virus-Associated Birth Defects, Costa Rica, 20162018. Emerg Infect Dis. 2021;27(2):360-371. doi: 10.3201/eid2702.202047

15. Leite RFP, Santos MSA, Ribeiro EM, Pessoa ALS, Lewis DR, Giacheti CM, et al. Hearing Screening in children with Congenital Zika Virus Syndrome in Fortaleza, Ceará, Brazil, 2016. Epidemiol Serv Saude. 2018;27(4):e2017553. doi: 10.5123/S167949742018000400002.

16. França GV, Schuler-Faccini L, Oliveira WK, Henriques CM, Carmo EH, Pedi VD, et al. ongenital Zika virus syndrome in Brazil: a case series of the first 1501 livebirths with complete investigation. Lancet. 2016;388(10047):891-7. doi: 10.1016/S01406736(16)30902-3.
17. Voordouw B, Rockx B, Jaenisch T, Fraaij P, Mayaud P, Vossen A, et al. Performance of Zika Assays in the Context of Toxoplasma gondii, Parvovirus B19, Rubella Virus, and Cytomegalovirus (TORCH) Diagnostic Assays. Clin Microbiol Rev. 2019;33(1):e00130-18. doi: 10.1128/CMR.00130-18

18. Magalhaes Barbosa M. Magalhaes Barboza MC, Rodríguez Robaina J, Prata-Barbosa A, Tavares de Lima. Alves da Cunha AJL. Auditory findings associated with Zika virus infection: an integrative review. Braz.J Otorhinolarygol. 2019;85(5):642-663. doi: 10.1016/j.bjorl.2019.05.002

19. Carney AE, Moeller M. Treatment efficacy: hearing loss in children. J Speech Lang Hear Res. 1998;41(1):61-84. doi: 10.1044/jslhr.4101.s61

20. Mittal R, Fifer RC, Liu XZ. A Possible Association Between Hearing Loss and Zika Virus Infections. JAMA Otolaryngol Head Neck Surg. 2018;144(1):3-4. doi: 10.1001/jamaoto.2017.1798.

21. Adebanjo T, Godfred-Cato S, Viens L, Fischer M, Staples E, Kuhnert-Tallman W, et al. Update: Interim Guidance for the Diagnosis, Evaluation, and Management of Infants with Possible Congenital Zika Virus Infection — United States, October 2017. MMWR Morb Mortal Wkly Rep. 2017;66(41):10891099. doi: 10.15585/mmwr.mm6641a1.

22. Ministerio de Salud y Protección Social (CO). Lineamientos para la atención clínica integral de pacientes con Zika en Colombia [Internet]. Bogotá: Ministerio de Salud y Protección Social; 2016. Disponible en: https://www.minsalud.gov.co/sites/ $\mathrm{rid} /$ Lists/BibliotecaDigital/RIDE/VS/PP/ET/lineamientos-atencion-clinica-integral-paciente-zika-colombia.pdf

23. Secretária da Saúde do Estado da Bahia (BR). Protocolo de atenção à gestante com suspeita de zika e à criança com microcefalia [Internet]. Bahia: Secretária da Saúde; 2016. Disponible en: http:// www.saude.ba.gov.br/wp-content/uploads/2017/09/ 
protocolo_de_atencao_a_gestante_com_suspeita_de_zika_e_crianca_com_microcefalia_versao1_09_03_2016.pdf

24. Centro Nacional de Epidemiología (ES). Protocolo de Vigilancia de la Enfermedad por Virus Zika. Protocolos de la Red Nacional de Vigilancia Epidemiológica [Internet]. Madrid: Centro Nacional de Epidemiología; 2019. Disponible en: https://www. isciii.es/QueHacemos/Servicios/VigilanciaSaludPublicaRENAVE/EnfermedadesTransmisibles/Documents/PROTOCOLOS/PROTOCOLOS\%20EN\%20 BLOQUE/PROTOCOLOS\%20VECTORES/protocolos\%202019/PROTOCOLO\%20ZIKA_20190726. pdf

25. Ministerio de Salud (SV). Lineamientos Técnicos para la Atención Integral de personas con Zika [Internet]. San Salvador: Ministerio de Salud; 2016. Disponible en: http://asp.salud.gob.sv/regulacion/ pdf/lineamientos/lineamientos_tecnicos_atencion_ integral_zika_v2.pdf

26. Ministerio de Salud Pública y Bienestar Social (PY). Protocolo de Vigilancia Infección por Virus Zika [Internet]. Asunción: Ministerio de Salud Pública y Bienestar Social; 2019. Disponible en: https:// www.zikacommunicationnetwork.org/sites/default/ files/resource_files/PVIZIKA\%202019_final\%20 con\%20resolucion.pdf

27. Ministerio de Salud (NI). Guía de práctica clínica para la atención a la embarazada y vigilancia del Síndrome Congénito asociado a la infección por el virus del Zika [Internet]. Managua: Ministerio de Salud; 2018. Disponible en: http://www.minsa.gob. ni/index.php/repository/func-download/4325/chk,809f6d5590c9b8ec876ff5cc2cb7e9f0/no_html,1/

28. Morilla Guzmán A, Álvarez Fumero R. Recomendaciones para la atención a hijos recién nacidos de madres con diagnóstico de virus Zika en Cuba. Rev Cubana Pediatr [Internet]. 2017;89(4):1-14. Disponible en: http://scielo.sld.cu/pdf/ped/v89n4/ ped16417.pdf

29. Qualls N, Levitt A, Kanade N, Wright-Jegede N, Dopson S, Biggerstaff $M$, et al. Community Mitigation Guidelines to Prevent Pandemic Influenza - United States, 2017. MMWR Recomm Rep. 2017;66(1):1-34. doi: 10.15585/mmwr.rr6601a1. 